\section{Editorial: On IRIE Vol. 5}

Have you seen a doctor lately? We hope not (at least not in an unpleasant matter). Anyway, if so you could have seen for yourself that modern medicine has become almost inconceivable without the use of information technology: from getting an appointment in the first place up to the making of a diagnosis, the treatment and not to forget all the accounting and necessary archiving. In fact it radically changed the delivery of health care in various aspects. And even more fundamentally - at least that is what some authors of this issue argue information technology has transformed the medical construction of the human body and the scientific understanding of disease itself.

No one can deny the great improvements that have been made possible by these developments. Being aware of this massive further research and development is undertaken in the field. Not less important it is then to be aware of the ethical issues raised: the benefits and risks for the patient, the practitioner and the society thus developing guide lines for an appropriate use of information technology in medicine and health care.

Any normative analysis in this field has to be based on a thorough factual understanding of the technological developments, their medical applications and qualified philosophical interpretations. Therefore, we are very thankful that this issue is once again coedited by two very experienced experts in the field: Georg Marckmann, Dept. of Medical Ethics at the University of Tübingen, Germany, and Kenneth W. Goodman, Director of the Bioethics Program and CoDirector, Ethics Program, at Miami University, USA. Due to their excellent piece of work, we can publish six very profound contributions to the subject in this issue ranging from an analysis of the role of software in the patient care process up to questions on property and availability of genetic information. For an overview of the different contributions see the very compound and well informed introduction Georg Marckmann and Kenneth Goodman wrote at the beginning of this volume.

We therefore are convinced that this issue of IRIE provides a most welcome forum to analyse and discuss the ethical and social issues raised by the various applications of information and communication technology in medicine and health care. May it lead to deeper insights, open controversies and new perspectives for scholars and practitioners all over the world.

Having no book reviews included in this issue we take the advantage to encourage you to contact us actively if you intend to contribute one or would like to have a specific book reviewed. IRIE is open to reviews of all kind of books in the field of Information Ethics - not only those dealing with the current subject of an issue.

Once again an article not belonging to the major subject of this issue complements this volume. It is James D. Caufiled's 'Myth of automated meaning' unmasking uncredited human processes in the generation of search engine results. We didn't want to withhold this interesting point of view supplementing our issue No. 3 explicitly dealing with the subject of search engines. That issue gained not only a great deal of attention but also the matters it dealt with keep on to be debated vividly in the scientific community. That is finally what we intended and what we hope for this compelling issue on the Ethics of Information Technology in Medicine and Health Care as well.

Yours,

Rafael Capurro, Thomas Hausmanninger, Karsten Weber and Felix Weil 